\title{
Utilização do laser de argônio na remoção de sutura
} corneana

\author{
Use of argon laser in corneal suture removal
}

\author{
Edélcio Vieira ${ }^{1}$ \\ Vinícius dos Santos Watzl Costa Lima² \\ Mírian da Silva Azevedo ${ }^{3}$ \\ Wantuil Ferreira de Souza Júnior ${ }^{3}$ \\ Roberto Reis Xavier dos Santos ${ }^{4}$ \\ Ruiz Simonato Alonso ${ }^{5}$
}

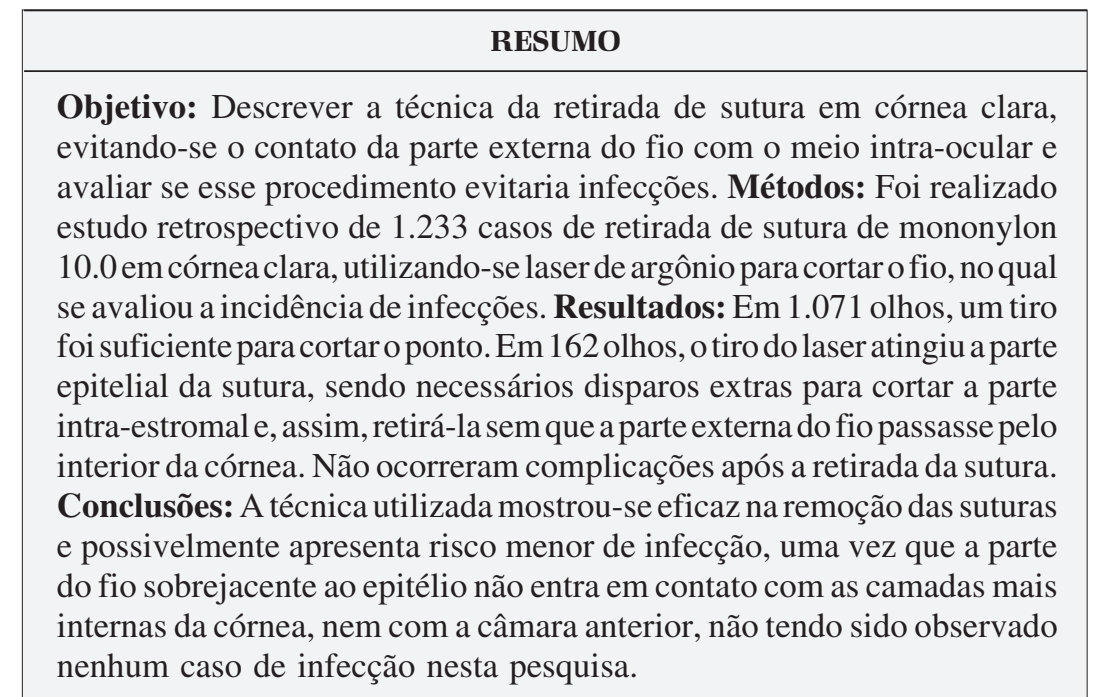

Descritores: Sutura, Córnea/cirurgia; Laser/efeitos adversos; Facoemulsificação; Estudo retrospectivo

\section{INTRODUÇÃ̃O}

Inúmeras vezes depara-se com a necessidade de suturar a córnea, seja devido a trauma corto-contuso, transplante corneano ou mais freqüentemente na cirurgia da catarata. Alguns trabalhos versam sobre endoftalmite após a facoemulsificação sem sutura ${ }^{(1-2)}$. Segundo estudo de Cooper e colaboradores, a incisão em córnea clara nessa cirurgia, apresenta uma incidência três vezes maior desse tipo de complicação ${ }^{(3)}$.

Se o ponto não for retirado, poderá induzir a complicações como: conjuntivite papilar gigante, úlcera corneana ${ }^{(4)}$, conjuntivite tarsal, conjuntivite purulenta, ceratite filamentosa, vascularização corneana, erosão do epitélio corneano, ceratite supurativa ${ }^{(5)}$, ou ceratite de aparecimento tardio, podendo levar a endoftalmite ${ }^{(6)}$. Além das complicações acima, há relatos de alergia ao próprio nylon ${ }^{(7)}$.

Foram evidenciados, em estudos científicos, depósitos de proteínas e bactérias na sutura da córnea ${ }^{(8-10)}$.

Têm sido relatadas, embora raramente, complicações tais como úlcera de córnea e endoftalmite depois da retirada de ponto corneano ${ }^{(11-15)}$ ou sua ruptura espontânea ${ }^{(16)}$. Essas complicações ocorreram com vários tipos de cirurgias, inclusive cirurgia de catarata.

O presente trabalho foi idealizado com a finalidade de descrever a técnica da retirada de sutura em córnea clara, utilizando o laser de argônio, evitando-se o contato da parte externa do fio com o meio intra-ocular e avaliar se esse procedimento evitaria infecções. 


\section{MÉTODOS}

Trata-se de um estudo retrospectivo realizado entre $1999 \mathrm{e}$ 2003. Neste período foram feitas, na Clínica de Olhos Zona Oeste, 2.788 facectomias com facoemulsificação e implante de lente intra-ocular, utilizando-se um ponto na incisão. Destas, apenas $1.260(45,1 \%)$ foram incluídas, por terem sido submetidas à retirada do ponto com laser de argônio (Figura $1 \mathrm{e}$ Gráfico 1). Foram excluídas do estudo 1.528 facectomias, nas quais a remoção não foi efetuada com a utilização do laser.

Foram pesquisadas complicações per operatórias, como lesões no estroma corneano induzido pelo laser, e pós-operatórias como edema de córnea, úlcera de córnea e endoftalmite.

O disparo do laser foi feito na parte intra-estromal da sutura evitando a rotação da parte externa do fio para o interior da córnea, durante a sua remoção.

Todos os procedimentos foram feitos pelo mesmo médico (E.V.), a partir do $15^{\circ}$ dia de pós-operatório, precedidos pelo uso de iodo povidona a 5\%, adotando-se os seguintes parâmetros técnicos, no aparelho Visulas - Carl Zeiss ${ }^{\circledR}$ (Alemanha):

Posição do paciente:

- Infra-abdução do olho a ser submetido ao procedimento (quando a sutura foi realizada na posição de 11 horas). Quando o sítio do ponto foi diferente do mencionado, a mirada do paciente foi a que possibilitasse a melhor exposição da parte intra-estromal da sutura.

- Potência: $0,340 \mathrm{~W}$.

- Spot: 50 a $100 \mu \mathrm{m}$.

- Tempo: $0,1 \mathrm{~s}$.

- Aumento de 16 vezes.

- Foco na parte intra-estromal (Figura 2).

O corte foi feito na parte interna da sutura próximo ao nó (Figura 1). Um disparo geralmente é suficiente (Figura 1), mes-

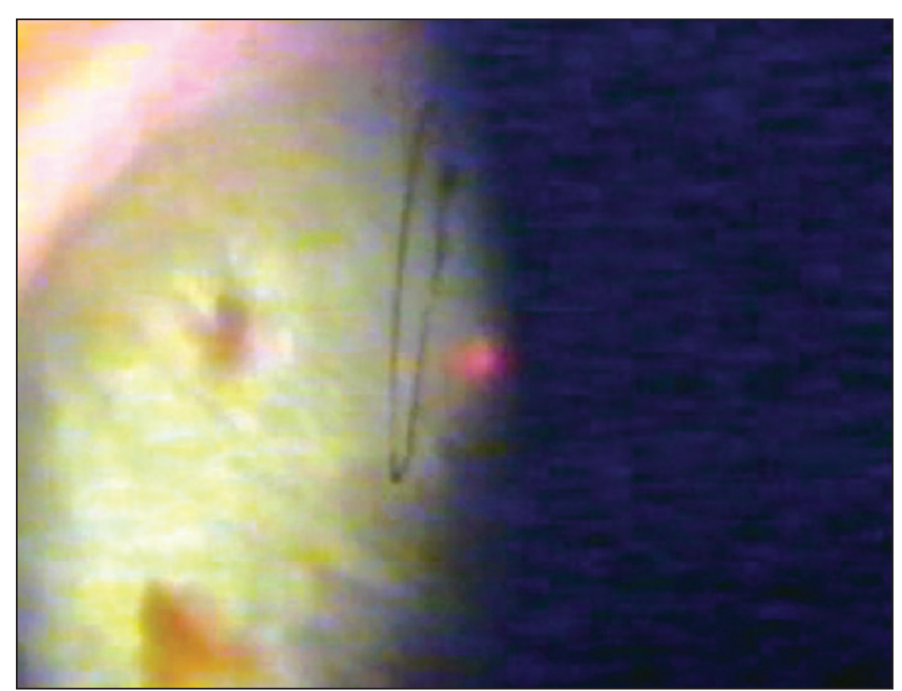

Figura 1 - Retirada de ponto com laser de argonio. O corte do fio é feito na parte intra-estromal da sutura. A retirada deste ocorre sem que haja rotação da parte externa para a interna, com isto o procedimento é mais seguro, quanto ao evitar infecções

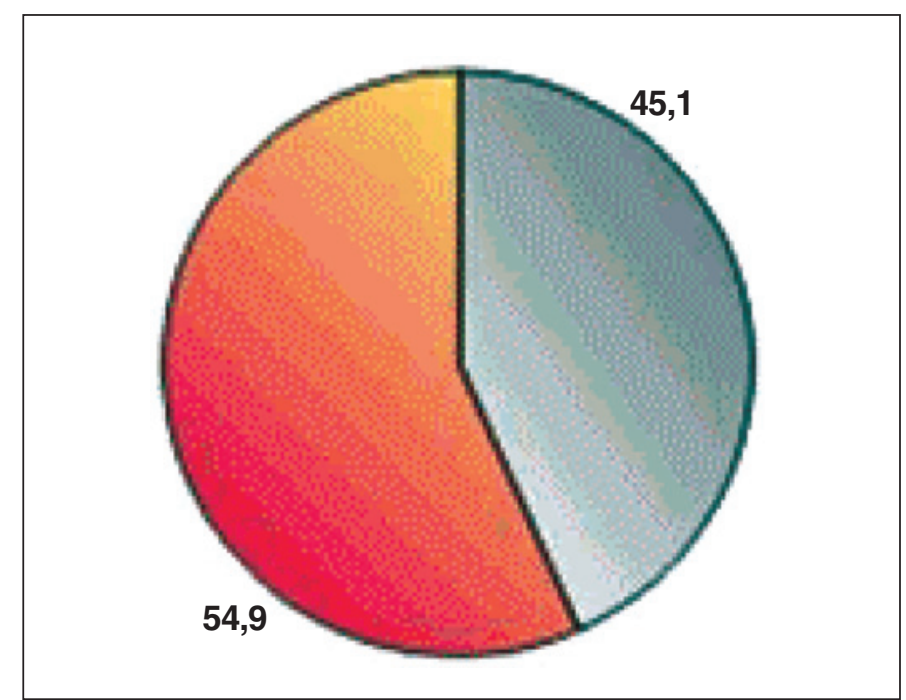

Gráfico 1 - Destinação das suturas de pacientes submetidos à facoemulsificação. A cor cinza mostra os pacientes que retiraram o ponto com laser de argônio. A coloração vermelha demonstra os que não utilizaram o laser na sua retirada ou não removeram a sutura

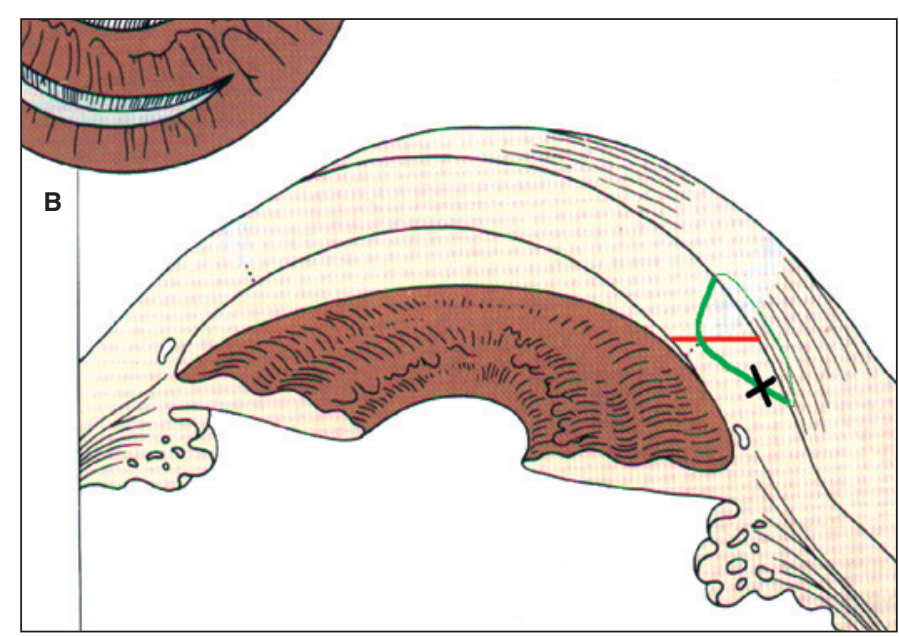

Figura 2 - Figura mostrando onde se deve posicionar o nó ao ser confeccionado o ponto (em preto), em relação à incisão (em vermelho). A cor verde identifica a sutura

mo que o corte não seja total. O local fica esbranquiçado e frágil e o fio arrebenta facilmente quando tracionado. A movimentação do olho pelo paciente pode criar dificuldade durante o procedimento, fazendo com que o laser atinja a parte epitelial da sutura. Caso isso ocorra, deve-se proceder a nova tentativa para cortar o fio na parte intra-estromal também. Assim, ao invés de fazer uma retirada única, esse procedimento deve ser realizado duas vezes.

Após a aplicação do laser, a sutura foi extraída pela parte epitelial, utilizando uma pinça de córnea, esterilizada em autoclave.

Nota: Apesar de alguns autores preconizarem uma potência de 600 a $800 \mathrm{~mW}^{(17)}$, observa-se que apenas $340 \mathrm{~mW}$ são 
suficientes para o corte da sutura, ocasionando um menor trauma para a córnea.

\section{RESULTADOS}

A técnica foi realizada com sucesso em todos os casos. Dos pacientes que não retiraram o ponto com laser, apenas um apresentou complicação: úlcera de córnea, seguida de endoftalmite, no segundo ano de pós-operatório. A ulceração corneana ocorreu no local em que o ponto rompeu-se por biodegradação. Outras complicações como, conjuntivite papilar gigante, conjuntivite tarsal, conjuntivite purulenta, ceratite filamentosa, vascularização corneana, erosão do epitélio corneano e ceratite supurativa, não foram observadas neste estudo.

Com a utilização desta técnica e com os parâmetros descritos, não se observou nenhum caso de edema de córnea, infecção corneana ou intra-ocular.

\section{DISCUSSÃO}

A infecção intra-ocular, após a retirada do ponto, é mais frequiente quando se tem vazamento da ferida mas pode ocorrer mesmo sem a presença deste ${ }^{(1)}$. Outros fatores, como o uso de corticosteróides ${ }^{(14)}$ e baixa imunidade ${ }^{(15)}$ podem ter influenciado nas complicações da retirada de sutura com agulha mencionadas em outros trabalhos ${ }^{(14-15)}$. Este procedimento tem uma importância crucial se a sutura transfixa toda a córnea ou quando existe parte da íris aderida ao fio ${ }^{(17)}$, neste caso, corta-se a parte proximal e distal do fio junto à íris e retira-se o resto. Para prevenir este tipo de complicação, deve-se evitar transfixar toda a espessura corneana com a agulha de sutura ${ }^{(14)}$.

Existe trabalho relatando não haver diferença entre a incidência de infecção na cirurgia de catarata com ou sem sutu$\mathrm{ra}^{(18)}$, porém este foi feito baseado na incisão escleral e não em córnea clara. Possivelmente, na incisão em córnea clara a possibilidade de vazamento e enchimento por aspiração da câmara anterior quando o olho é submetido a uma pressão (o ato de coçar por exemplo) no pós-operatório imediato é maior do que na incisão escleral, recoberta pela conjuntiva.

A síntese da incisão (mesmo sendo auto-selante) é importante para evitar a infecção no pós-operatório da facoemulsificação em córnea clara ${ }^{(1-2)}$, seja ela feita com sutura ${ }^{(19)}$ ou cola orgânica $^{(20)}$. A utilização de cola orgânica ainda é um método caro, sendo a sutura uma boa alternativa ${ }^{(20)}$.

Durante a sutura, ao rodar o nó, deve-se deixá-lo próximo ao orifício de saída da agulha (Figura 1). Pois se o nó ficar no meio do estroma, pode haver dificuldade na mira do laser.

\section{CONCLUSÕES}

O presente estudo mostrou que a remoção de sutura corneana pós-cirurgia de catarata, utilizando-se o laser de argônio é uma boa opção, não tendo sido observado nenhum caso de infecção ou qualquer outra complicação.

\section{AGRADECIMENTO}

A Paula Grativol, por sua colaboração na coleta de dados.

\section{ABSTRACT}

Purpose: To describe the technique of clear-cornea suture removal, that avoids the contact of the external part of the thread with the intraocular medium, and to evaluate whether this procedure would prevent infections. Methods: A retrospective study of 1.233 cases of clear-cornea mononylon 10.0 suture removal, by the use of an argon laser to cut the thread, was performed. Incidence of infection was then assessed. Results: In 1.071 eyes, one shot was enough to cut the stitch. In 162 eyes, the laser shot hit the epithelial part of the suture, making new shots necessary to cut the intrastromal part, and thus to remove it assuring that the outer part of the stitch would not come in to contact with the interior of the cornea. There were no complications after suture removal. Conclusions: The technique has shown to be effective in suture removal. And, possibly, presents a lower risk for infection, since the external part of the thread does not come in to contact with the innermost parts of the cornea, or with the anterior chamber. No cases of infection have been observed during this research.

Keywords: Suture; Cornea/surgery; Lasers/adverse effects; Phacoemulsification; Retrospective study

\section{REFERÊNCIAS}

1. Garg P, Mahesh S, Bansal AK, Gopinathan U, Rao GN. Fungal infection of sutureless self-sealing incision for cataract surgery. Ophthalmology. 2003;110 (11):2173-7

2. Perlstein SH, Edelstein MS, Chubak GS. Bacterial endophthalmitis following sutureless cataract surgery. Arch Ophthalmol. 1994;112(3):301-2.

3. Cooper BA, Holekamp NM, Bohigian G, Thompson PA. Case-control study of endophthalmitis after cataract surgery comparing scleral tunnel and clear corneal wounds. Am J Ophthalmol. 2003;136(2):300-5.

4. Sridhar MS, Sharma S, Garg P, Rao GN. Broken suture-predisposing factor for Nocardia keratitis. Eye. 2000;14(Pt 1):112-4.

5. Cameron JA, Huaman A. Corneoscleral abscess resulting from a broken suture after cataract surgery. J Cataract Refract Surg. 1994;20(1):82-3.

6. Khurshid GS, Fahy GT. Endophthalmitis secondary to corneal sutures: series of delayed-onset keratitis requiring intravitreal antibiotics. J Cataract Refract Surg. 2003;29(7):1370-2.

7. Jackson H, Bosanquet R. Should nylon corneal sutures be routinely removed? Br J Ophthalmol.1991;75(11):663-4.

8. Harris DJ Jr. Branhamella catarrhalis colonization of exposed nylon sutures. J Cataract Refract Surg. 1991;17(6):847-8.

9. Norn MS. Pus and mucus around sutures following cataract extraction studies by vital staining with tetrazolium-alcian blue mixture. Acta Ophthalmol (Copenh). 1972;50(1):95-101.

10. Heaven CJ, Davison CR, Cockcroft PM. Bacterial contamination of nylon corneal sutures. Eye. 1995;9(Pt 1):116-8.

11. Culbert RB, Devenyi RG. Bacterial endophthalmitis after suture removal. J Cataract Refract Surg. 1999;25(5):725-7.

12. Weiss J L, Nelson J D, Lindstrom R L, Doughman DJ. Bacterial endophthalmitis following penetrating keratoplasty suture removal. Cornea. 1984-85;3 (4):278-80. 
904 Utilização do laser de argônio na remoção de sutura corneana

13. Cohen JS, Osher RH. Endophthalmitis associated with releasable sutures. Arch Ophthalmol. 1997;115(2):292.

14. Forstot SL, Abel RJr, Binder PS. Bacterial endophthalmitis following suture removal after penetrating keratoplasty. Am J Ophthalmol. 1975;80(3 Pt 2):509-12.

15. Gelender H. Bacterial endophthalmitis following cutting of sutures after cataract surgery. Am J Ophthalmol. 1982;94(4):528-33.

16. Confino J, Brown SI. Bacterial endophthalmitis associated with exposed monofilament sutures following corneal transplantation. Am J Ophthalmol. 1985;99(2):111-3.
17. Metz D, Ackerman J, Kanarek I. Use of the argon laser in suture removal after cataract surgery. Am J Ophthalmol. 1984;97(3):393-4.

18. Turkalj JW, Carlson AN, Manos JP, Apple DJ. Is the sutureless cataract incision a valve for bacterial inoculation? J Cataract Refract Surg. 1995;21(4):472-6.

19. Speaker M. Diagnosis, management and prevention of endophthalmitis. Highlights Ophthalmol. 1993;21:89-94

20. Shigemitsu T, Majima Y. The utilization of a biological adhesive for wound treatment: comparison of suture, self-sealing sutureless and cyanoacrylate closure in the tensile strength test. Int Ophthalmol. 1996-97;20(6):323-8. 